\title{
Hedgehog/Gli promotes epithelial-mesenchymal transition in lung squamous cell carcinomas
}

\author{
Dongsheng Yue ${ }^{1,2,3 \dagger}$, Hui Li ${ }^{3 \dagger}$, Juanjuan Che ${ }^{4 \dagger}$, Yi Zhang ${ }^{5}$, Hsin-Hui K Tseng ${ }^{3}$, Joy Q Jin ${ }^{3}$, Thomas M Luh ${ }^{3}$, \\ Etienne Giroux-Leprieur ${ }^{3}$, Minli Mo ${ }^{6}$, Qingfeng Zheng ${ }^{3,7}$, Huaiyin Shi ${ }^{8}$, Hua Zhang ${ }^{1,2}$, Xishan Hao ${ }^{1,2^{*}}$, \\ Changli Wang ${ }^{1,2}$, David M Jablons ${ }^{3}$ and Biao $\mathrm{He}^{3^{*}}$
}

\begin{abstract}
Background: Squamous cell carcinomas (SCC) account for approximately 30\% of non-small cell lung cancer. Investigation of the mechanism of invasion and metastasis of lung SCC will be of great help for the development of meaningful targeted therapeutics. This study is intended to understand whether the activation of Hedgehog $(\mathrm{Hh})$ pathway is involved in lung SCC, and whether activated Hh signaling regulates metastasis through epithelial-mesenchymal transition (EMT) in lung SCC.

Methods: Two cohorts of patients with lung SCC were studied. Protein expression was examined by immunohistochemistry, Western blot, or immunofluorescence. Protein expression levels in tissue specimens were scored and correlations were analyzed. Vismodegib and a Gli inhibitor were used to inhibit Shh/Gli activity, and recombinant Shh proteins were used to stimulate the Hh pathway in lung SCC cell lines. Cell migration assay was performed in vitro.

Results: Shh/Gli pathway components were aberrantly expressed in lung SCC tissue samples. Gli1 expression was reversely associated with the expression of EMT markers E-Cadherin and $\beta$-Catenin in lung SCC specimens. Inhibition of the Shh/Gli pathway suppressed migration and up-regulated E-Cadherin expression in lung SCC cells. Stimulation of the pathway increased migration and down-regulated E-Cadherin expression in lung SCC cells.

Conclusions: Our results suggested that the Shh/Gli pathway may be critical for lung SCC recurrence, metastasis and resistance to chemotherapy. Inhibition of the Shh/Gli pathway activity/function is a potential therapeutic strategy for the treatment of lung SCC patients.
\end{abstract}

Keywords: Sonic Hedgehog, Gli, EMT, Lung squamous cell carcinoma

\section{Background}

Lung cancer is the leading cause of cancer-related deaths worldwide. 85\% of lung cancer is non-small cell lung cancer (NSCLC), with adenocarcinoma (AD) and squamous cell carcinoma (SCC) as the two major pathological subtypes [1]. Lung SCC is closely associated with tobacco smoking, and it accounts 35\% of NSCLC, causing an estimated 400,000 deaths per year worldwide [2]. While recent

\footnotetext{
*Correspondence: yuedongsheng_cg@163.com; biao.he@ucsfmedctr.org ${ }^{\dagger}$ Equal contributors

'Department of Lung Cancer, Lung Cancer Center, Tianjin Medical University Cancer Institute and Hospital, Tianjin 300060, China

${ }^{3}$ Department of Surgery, Thoracic Oncology Program, Helen Diller Family Comprehensive Cancer Center, University of California, San Francisco, CA 94115, USA

Full list of author information is available at the end of the article
}

improvements in targeted therapies such as the EGFR tyrosine kinase inhibitors (TKI), bevacizumab and ALK inhibitors have significantly benefited patients with $\mathrm{AD}$, the effectiveness of these treatments are unfortunately disappointing for lung SCC [3]. Lung SCC patients suffer from poor prognosis with significant rates of reoccurrence and metastasis, largely due to the differences in genetic profiles [4]. Recent studies identified potentially actionable genetic abnormalities in lung SCC, such as phosphoinositide 3kinase (PIK3CA) amplification, fibroblast growth factor receptor 1 (FGFR1) amplification, and discoidin domain receptor 2 (DDR2) mutation. However, significant efforts are still needed to help in the investigation of the 
biological characteristics of lung SCC in order to decipher and the mechanism underlying the invasion and metastasis of lung SCC.

Epithelial-mesenchymal transition (EMT) was originally characterized during embryonic development. The concept that EMT being a critical event in the invasion, progression and metastasis of epithelial cancers is well established [5,6]. The molecular basis of EMT involves multiple changes in expression, distribution, and/or function of proteins, i.e. E-cadherin, and the process of EMT is regulated by many molecular events including multiple signaling pathways in various cancers [5]. Furthermore, acquisition of the features of the EMT has been associated with poor prognosis and chemo-resistance, which may allow for recurrence and metastasis to occur after treatment with a standard chemotherapeutic treatment [7-10]. The mechanistic study of EMT regulation could contribute to our understanding of recurrence and metastasis in cancer.

Activation of Hedgehog $(\mathrm{Hh})$ signaling has been implicated in tumorigenesis and metastasis in various cancer types [11-23]. Hh signaling is orchestrated by two transmembrane receptors, Patched (Ptch) and Smoothened (Smo). In the canonical Hh pathway, in the absence of the Hh ligand, Ptch inhibits Smo, causing cleavage of Gli to the N-terminal repressor form. Once Hh binds to Ptch, the inhibitory effect on Smo is released, causing active full-length Gli to transport into the nucleus and activate transcription of $\mathrm{Hh}$ target genes in a contextand cell-type specific manner. Moreover, several studies have revealed "non-canonical Gli activation" in many cancer cell types by which Gli is activated independent of $\mathrm{Hh} / \mathrm{Smo}$ regulation $[12,14]$. It needs to be elucidated if the canonical Hh pathway or the non-canonical Gli activation is involved in lung SCC, and if Gli activation contributes to the regulation of metastasis.

Studies of EMT regulation by Hh pathway have recently emerged in literature; data, however, is rare and controversial. While Alexaki et al. [24] and Inaguma et al. [25] suggested that Gli-factor facilitates cancer cell migration and invasion through E-Cadherin in melanoma and pancreatic cancers, Joost et al. [26] proposed that inhibition of Gli promoted EMT in pancreatic cancers. Our study intends to extend the research to lung SCC to help us better understand the regulation of EMT by Hh signaling.

We reported the activation of Hh signaling in two cohorts of patient samples, and revealed the reverse association between Gli1 expression and the expression of EMT markers. Inhibition of the Shh/Gli pathway suppressed migration and up-regulated E-Cadherin expression in lung SCC cells. Stimulation of the pathway increased migration and down-regulated E-Cadherin expression in lung SCC cells.
A

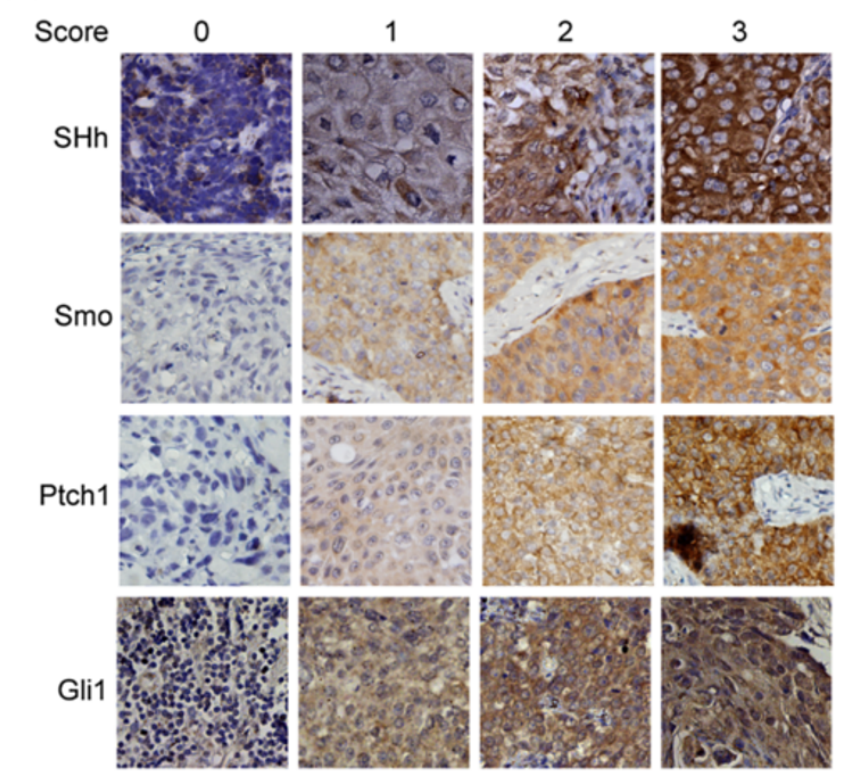

B
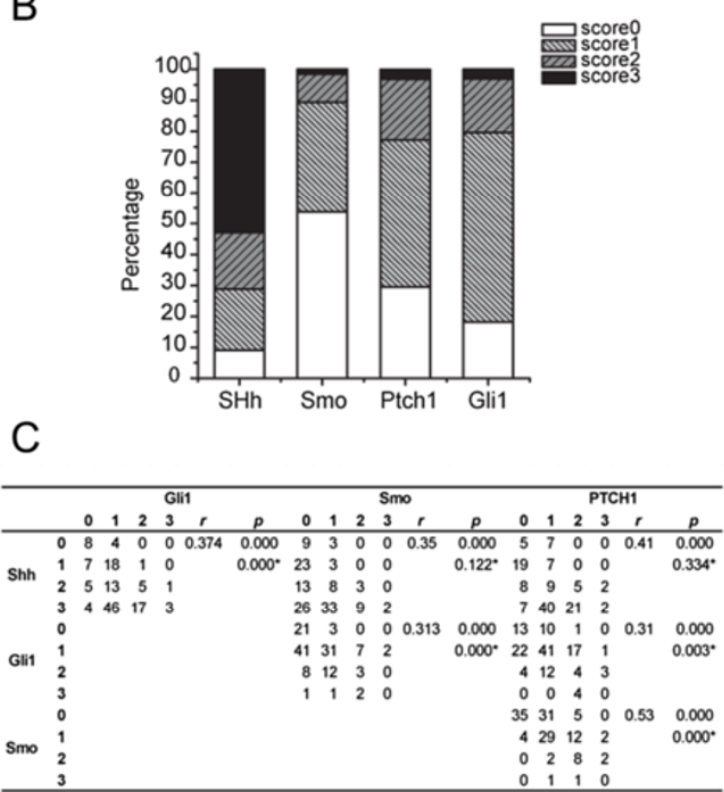

Figure 1 Aberrant activation of the Shh pathway in lung SCC. (A) Representative protein expression of Shh, Smo, Ptch1 and Gli1 by IHC staining, scored as 0 (negative), 1 (mild positive), 2 (positive), and 3 (strong positive). (B) Expression distributions of Shh, Smo, Ptch1 and Gli1 in 177 patient tissue specimens in the Tianjin cohort. (C) Association between the expressions of Hh pathway components. Kendall's tau-b statsitcs was used to determine the correlation between proteins. The correlation coefficient $r$ and $p$ values were presented in (C). Kappa test was also performed with IHC scores of 1-3 grouped as " + ", 0 as "-". Kappa test's $p$ values were labeled with*. 


\section{Materials and methods Tissue specimens}

Tissue specimens of the UCSF cohort were collected from 14 patients who underwent surgical resection for lung SCC at the Thoracic Oncology Program at UCSF. Tissue specimens of the Tianjin cohort were collected from 177 patients who underwent surgical resection for lung SCC at the Tianjin Medical University Cancer Institute and Hospital. Samples were fixed in formalin and embedded in paraffin to make tissue slides. The study with UCSF patient tissues was approved by the Committee on Human Research (CHR approval number: H8714-11647-10) at the University of California, San Francisco (UCSF), and that with Tianjin cohort was approved by the Tianjin Medical University Cancer Institute and Hospital. Written, informed consent was obtained from each patient before specimen collection.

\section{Immunohistochemistry (IHC), immunofluorescence (IF)} and Western blot

Immunohistochemistry, immunofluorescence and western blot were performed following standard procedures. Antibodies applied to detect protein expressions in IHC and IF were Gli1 (sc-20687 Santa Cruz Biotechnology, Santa Cruz, CA) at 1:100, Shh (ab 50515 Abcam, Cambridge, MA) at 1:100, Smo (ab 72130 Abcam) at 1:200, Ptch1 (Santa Cruz that Biotechnology,) and E-Cadherin (EMD Millipore) Smo (Sigma, St. Louis, MO) at 1:100, E-cadherin (sc-7870, Santa Cruz Biotechnology) at 1:100, and $\beta$-catenin (BD Biosciences, San Jose, California) at 1:400. Antibodies used in Western blot were Gli $(\mathrm{C} 68 \mathrm{H} 3$, Abcam) at 1:1000, E-Cad (HECD-1 MED Milliopore, Darmstadt, Germany) at 1:1000 and Actin (A5441, Sigma) at 1:5000. Total protein extraction was performed with M-PER Mammalian Protein Extraction Solution (Thermo Scientific, Waltham, MA), and 40ug of proteins were analyzed in Western blot.

\section{Cell culture, drug treatment and migration assay}

Human lung SCC cell lines H2170, H1703, H1869 and SK-MES-1 were purchased from the Cell Culture Core Facility at Harvard University (Boston, MA, USA). The cell lines were cultured in RPMI 1640 (Life Technologies, Carlsbad, CA) supplemented with 10\% fetal bovine serum (FBS) and antibiotics. Cells were seeded one day before treatment with Gli-I and vismodegib (Selleck) at different concentrations and Shh recombinant proteins (eBioscience) for 30 hours, with vehicle (DMSO) as controls. Cells were subjected to the following analyses of immunofluorescence and migration assay. In migration assays, four wounds were made in each condition, and cell migration was presented by the average of distance differences between $30 \mathrm{hr}$ and $0 \mathrm{hr}$. All experiments have been conducted for more than three times, and representative results were included in the text.

\section{Statistical analysis}

Kappa test was used to evaluate the association between the expressions of Hh pathway components and EMT markers, and between Gli1 and recurrence/metastasis. IHC scores of 1-3 were grouped as positive "+" , and 0 was grouped as negative "-" for dichotomized analysis. Non-parametric Kendall's tau-b statistics was used to determine the correlation between IHC staining of Hh components. Two-sided student's t-test was performed for migration assays. A p value $<0.05$ was indicated as *, 0.01 as $^{* *}$, and 0.001 as $* * *$ in corresponding figures. Data analysis was performed using SPSS 17.0 software.

\section{Results and discussion}

Aberrant activation of the Shh pathway in lung SCC

We first investigated the protein expression of key Shh pathway components in lung SCC tissue samples.

\section{Table 1 Characteristics of the lung SCC patients (Tianjin} cohort)

\begin{tabular}{|c|c|c|}
\hline Characteristics & No & Percent \\
\hline \multicolumn{3}{|l|}{ Age (Years) } \\
\hline$<60$ & 71 & $40.1 \%$ \\
\hline$\geq 60$ & 106 & $59.9 \%$ \\
\hline \multicolumn{3}{|l|}{ Gender } \\
\hline Male & 151 & $85.3 \%$ \\
\hline Female & 26 & $14.7 \%$ \\
\hline \multicolumn{3}{|l|}{ Smoking history } \\
\hline Never & 29 & $16.4 \%$ \\
\hline Smoker & 148 & $83.6 \%$ \\
\hline \multicolumn{3}{|l|}{ Surgical Procedure } \\
\hline Lobectomy & 143 & $80.8 \%$ \\
\hline Pneumonectomy & 30 & $16.9 \%$ \\
\hline Extend & 4 & $2.3 \%$ \\
\hline \multicolumn{3}{|l|}{ T stage } \\
\hline $\mathrm{T} 1$ & 45 & $25.4 \%$ \\
\hline $\mathrm{T} 2$ & 107 & $60.5 \%$ \\
\hline T3 & 25 & $14.1 \%$ \\
\hline \multicolumn{3}{|l|}{$\mathrm{N}$ stage } \\
\hline No & 126 & $71.2 \%$ \\
\hline N1 & 16 & $9.0 \%$ \\
\hline N2 & 35 & $19.8 \%$ \\
\hline \multicolumn{3}{|l|}{ TNM Stage } \\
\hline I & 91 & $51.4 \%$ \\
\hline$\|$ & 48 & $27.1 \%$ \\
\hline\|\|$A$ & 38 & $21.5 \%$ \\
\hline
\end{tabular}


Formalin-fixed, paraffin-embedded (FFPE) tissue specimens were collected from 177 lung SCC patients who underwent surgical resection at the Lung Cancer Center at Tianjin Medical University Cancer Institute and Hospital. The protein expressions of Shh, Smo, Ptch1 and Gli1 were characterized by immunohistochemistry (IHC), and scored on a scale of $0-3$ (negative, mild positive, positive, and strong positive). Representative samples in each score category were summarized in Figure 1A. More than $90 \%$ of the lung SCC tissue samples examined were positive for the signal molecule Shh, while $53 \%$ and $61 \%$ were positive for downstream components and transcriptional targets Ptch1 and Gli1 respectively (Figure 1B). Previous studies have demonstrated limited expressions of Shh components in normal lung tissues at the mRNA and protein levels in NSCLC $[27,28]$, therefore the expression of key Shh signaling components indicates the activation of Shh pathway. No significant association was found between expressions of Shh, Smo, Ptch1 and Gli1 and patients' characteristics (sex, age, tumor size, or degree of tumor differentiation) (Table 1$)(P>0.05$, data note shown).

Next we analyzed the association between expressions of key components in the Shh pathway. Kendall's tau-b correlation tests yielded significant correlations between every two factors $(p=0.000)$, while Kappa's test suggested strong positive association between SHh and Gli1 $(p=0.000)$ (Figure 1C), suggesting the canonical Shh pathway is activated in lung SCC. These data are consistent
A

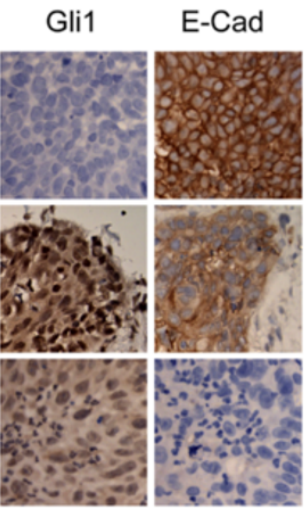

B

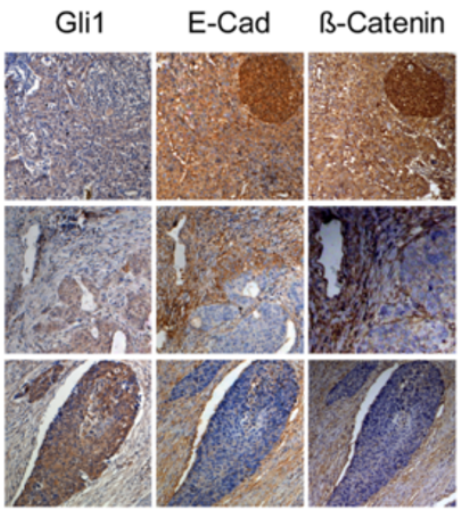

C

\begin{tabular}{ccccccccccc}
\hline & \multicolumn{3}{c}{ E-Cadherin } & \multicolumn{3}{c}{ B-Catenin } & \multicolumn{3}{c}{$\begin{array}{c}\text { Recurrence } \\
\text { /metastasis }\end{array}$} \\
\hline & - & + & $p$ & - & + & $p$ & - & + & $p$ \\
Gli1 - & 9 & 15 & 0.003 & 22 & 2 & 0.004 & 19 & 5 & 0.033 \\
+ & 75 & 33 & & 67 & 41 & & 60 & 48 & \\
\hline
\end{tabular}

D

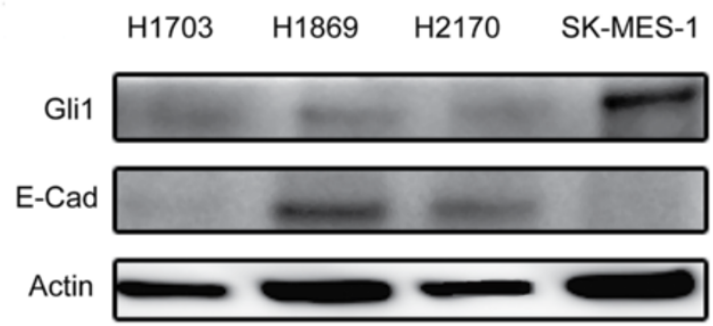

Figure 2 Gli1 expression reversely correlates with E-Cadherin expression in lung SCC. (A) Expressions of Gli1 and E-Cadherin (E-Cad) in three representative tissue specimens in the UCSF cohort with Gli1 expression at a low level (upper panels) and high levels (middle and lower panels). (B) Expressions of Gli1, E-Cad and $\beta$-Catenin ( $\beta$-Cat) in three representative tissue specimens in the Tianjin cohort with Gli1 expression at a low level (upper panels), a mixed expression pattern (middle panels) and a high level (lower panels). (C) Correlations between Gli1, EMT markers, and recurrence/metastasis. Statistical analysis was performed between Gli1 and E-Cad, Gli1 and $\beta$-Cat, Gli1 and recurrence/ metastasis. (D) Gli1 and E-Cad expression in four lung SCC cell lines by Western blots. 
with previous reports that the upstream Shh signaling has correlations with downstream targets in NSCLC $[29,30]$. Taken together, our results suggest that aberrant activation of the Shh pathway plays an important role in lung SCC.

\section{Gli expression reversely correlates with EMT markers}

E-Cadherin is a well-established EMT biomarker, and its expression has been suggested to be associated with cancer recurrence and metastasis [5]. The expression of $\beta$-Catenin also serves as a biomarker for EMT [31]. To investigate whether the Shh/Gli signaling plays a role in EMT regulation in lung SCC, we first examined 14 lung SCC patients who underwent surgical resection for lung SCC at the Thoracic Oncology Program at UCSF. Eight of fourteen samples showed reverse correlation between E-Cadherin and Gli1 expressions (three representative samples were shown in Figure 2A). To confirm the reverse correlation between EMT markers and
Gli1 expressions in lung SCC, we further analyzed ECadherin and $\beta$-Catenin expressions and correlated with Gli1 expression in the Tianjin cohort. Our results revealed strong reverse correlations between Gli1 and E-Cadherin $(p=0.003)$, as well as Gli1 and $\beta$-Catenin $(p=0.004)$ (Figures $2 \mathrm{~B}$ and $\mathrm{C})$. We also observed reverse correlation between Gli1 and E-Cadherin expression at different areas within one sample in multiple cases due to the heterogeneity of tumor cells (Figure 2), further supporting the reverse correlation between Gli1 and EMT marker expressions. Moreover, our analysis revealed that Gli1 significantly correlated with recurrence and metastasis of lung SCC in the Tianjin cohort $(p=0.033$; Figure 2C). Consistent with the tissue expression analysis, we observed that Gli1 expression reversely correlated with E-Cadherin expression in four human lung SCC cell lines, H1703, H1869, H2170 and SK-MES-1 (Figure 2D). Taken together, our results indicate the essential role of Gli1, a downstream effector

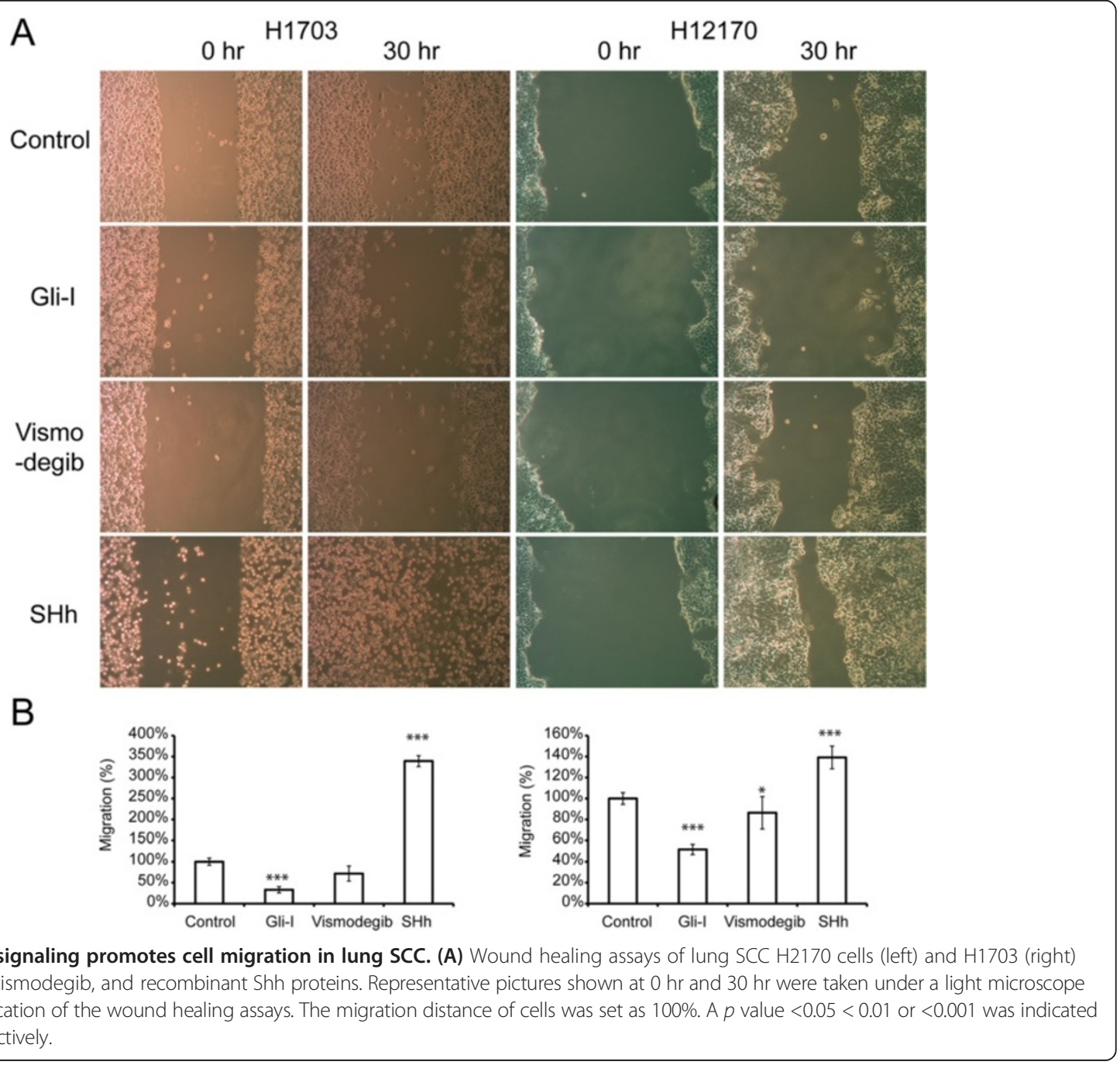




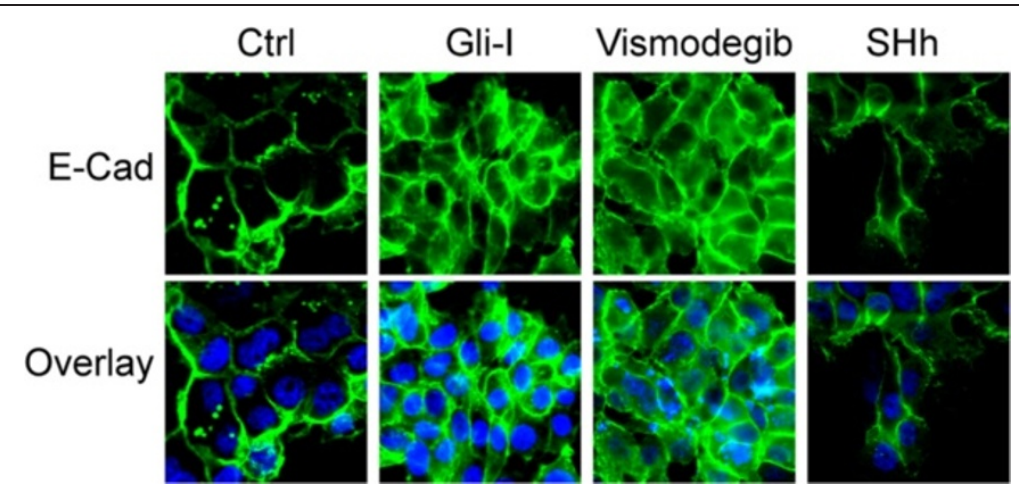

Figure 4 Shh/Gli signaling down-regulates E-Cadherin expression. Immunofluorescent staining of E-Cad (green) in lung SCC H2170 cells treated with Gli-I, vismodegib, and recombinant Shh proteins. DAPI (blue) was used to stain nuclei of those cells.

of Shh pathway, in enhancing EMT, which in turn promotes recurrence and metastasis in lung SCC.

\section{Shh/Gli signaling promotes cell migration by down-regulating E-Cadherin expression}

To further understand the role of Shh/Gli in EMT regulation in lung SCC, we manipulated the Shh/Gli signaling pathway in lung SCC cell lines to examine its impact on cell migration and E-Cadherin expression. To inhibit the Shh/Gli activity, we applied two small molecule compounds: Vismodegib and a novel Gli inhibitor. Vismodegib (also known as GDC-0449) is a Smo inhibitor recently approved by the U.S. Food and Drug Administration to treat adult patients with basal cell carcinoma [32-35]. Multiple clinical trials are evaluating the use of vismodegib in other types of cancer, in addition to other candidate drugs that targets Hh signaling $[32,36]$. The novel Gli inhibitor (Gli-I) developed by our lab specifically inhibits Gli1 and Gli2 transcriptional activity [28]. To stimulate the pathway, we applied recombinant Shh proteins.

We first performed cell migration assay in lung SCC cell lines H1703 and H2170 after the treatments with either Shh/Gli inhibitors or recombinant Shh proteins. Cells treated with Vismodegib and Gli-I exhibited significantly slower migration in 30 hours; on the other hand, cells stimulated by Shh proteins migrated significantly faster (Figure 3). This data strongly suggests that Shh/Gli signaling plays an essential role in regulating the migration of lung SCC cells. Next we examined E-Cadherin expression in these cells by immunofluorescence staining. We observed that E-Cadherin expression was up-regulated in those lung SCC cells treated with Shh/Gli inhibitors and down-regulated in the cells stimulated by Shh proteins (Figure 4). This is consistent with the mobility of lung SCC cells after the different treatments (Figure 3). Therefore, our results indicate that Shh/Gli signaling may promote cell migration by downregulating E-Cadherin expression in lung SCC.

\section{Conclusions}

Our study provides evidence for aberrant activation of Shh/Gli pathway and a strong association between expressions of Gli proteins and EMT markers in human lung SCC, as well as the implication of activated Shh/Gli pathway in cell migration and EMT process. Our findings suggest that the Shh/Gli pathway may be a critical component in lung SCC recurrence, metastasis and resistance to chemotherapy. Inhibition of the Shh/Gli pathway activity/ function is a potential therapeutic strategy for the treatment of lung SCC patients.

\section{Competing interests}

The authors declare that they have no competing interests.

\section{Authors' contributions}

DY carried out IHC staining, data analysis, and drafting of the manuscript. $\mathrm{HL}$ carried out IF staining, Western blotting, data analysis and drafting of the manuscript. JC, YZ, MM, QZ, and HZ carried out IHC staining and data analysis. HS carried out statistical analysis. HT, JJ, TL, and EG-L carried out the cell cultures and cell-based assays. DMJ participated in the study design and helped to draft the manuscript. CW, XH and BH conceived of the study, and participated in its design and coordination, and helped to draft the manuscript. All authors read and approved the final manuscript.

\section{Acknowledgements}

This work was supported by NIH/NCI R01CA125030, and the Eileen D. Ludwig Endowed for Thoracic Oncology Research (to B He); The Bonnie J. Addario Lung Cancer Foundation, the Kazan, McClain, Abrams, Fernandez, Lyons, Greenwood, Harley \& Oberman Foundation, the Ziegelmam Family Foundation, and the Barbara Isackson Lung Cancer Research Fund (to DM Jablons); Tianjin Municipal Science and Technology Commission (12JCYBJC17800) and the Key Program for Anti-cancer Research of Tianjin Municipal Science and Technology Commission (12ZCDZSY15400) (to CL Wang).

\section{Author details}

'Department of Lung Cancer, Lung Cancer Center, Tianjin Medical University Cancer Institute and Hospital, Tianjin 300060, China. ${ }^{2}$ Key Laboratory of Cancer Prevention and Therapy, National Clinical Research Center of Cancer, Tianjin 300060, China. ${ }^{3}$ Department of Surgery, Thoracic Oncology Program, Helen Diller Family Comprehensive Cancer Center, University of California, San Francisco, CA 94115, USA. ${ }^{4}$ Department of Oncology, Beijing Friendship Hospital of Capital Medical University, Beijing 100050, China. ${ }^{5}$ Department of Thoracic Surgery, Xuanwu Hospital, Capital Medical University, Beijing 100053, China. 'School of Life Sciences, Tsinghua University, Beijing 10084, China. ${ }^{7}$ Key Laboratory of Carcinogenesis and Translational Research (Ministry 
of Education), Thoracic Surgery II, Peking University Cancer Hospital \& Institute, Beijing 100142, China. ${ }^{8}$ Department of pathology, Chinese PLA General Hospital, Fu-xing Road \#28, Beijing 100853, China.

Received: 21 February 2014 Accepted: 15 April 2014 Published: 24 April 2014

\section{References}

1. Siegel R, Ma JM, Zou ZH, Jemal A: Cancer statistics. CA Cancer J Clin 2014, 64:9-29.

2. Travis WD: Pathology of lung cancer. Clin Chest Med 2012, 32:669.

3. Drilon A, Rekhtman N, Ladanyi M, Paik P: Squamous-cell carcinomas of the lung: emerging biology, controversies, and the promise of targeted therapy. Lancet Oncol 2012, 13:E418-E426.

4. Little AG, Gay EG, Gaspar LE, Stewart AK: National survey of non-small cell lung cancer in the United States: Epidemiology, pathology and patterns of care. Lung Cancer 2007, 57:253-260.

5. de Craene B, Berx G: Regulatory networks defining EMT during cancer initiation and progression. Nat Rev Cancer 2013, 13:97-110.

6. Hong KO, Kim JH, Hong JS, Yoon HJ, Lee JI, Hong SP, Hong SD: Inhibition of Akt activity induces the mesenchymal-to-epithelial reverting transition with restoring E-cadherin expression in $\mathrm{KB}$ and $\mathrm{KOSCC}-25 \mathrm{~B}$ oral squamous cell carcinoma cells. J Exp Clin Cancer Res 2009, 28:28-38.

7. Soltermann A, Tischler V, Arbogast S, Braun J, Probst-Hensch N, Weder W, Moch H, Kristiansen G: Prognostic significance of epithelial-mesenchymal and mesenchymal-epithelial transition protein expression in non-small cell lung cancer. Clin Cancer Res 2008, 14:7430-7437.

8. Yang MH, Wu MZ, Chiou SH, Chen PM, Chang SY, Liu CJ, Teng SC, Wu KJ: Direct regulation of TWIST by HIF-1 alpha promotes metastasis. Nat Cell Biol 2008, 10:295-305.

9. Vendrell JA, Thollet A, Nguyen NT, Ghayad SE, Vinot S, Bieche I, Grisard E, Josserand V, Coll JL, Roux P, Corbo L, Treilleux I, Rimokh R, Cohen PA: ZNF217 is a marker of poor prognosis in breast cancer that drives epithelial-mesenchymal transition and invasion. Cancer Res 2012, 72:3593-3606.

10. van den Broeck A, Vankelecom H, van Eijsden R, Govaere O, Topal B: Molecular markers associated with outcome and metastasis in human pancreatic cancer. J Exp Clin Cancer Res 2012, 31:68-77.

11. Lauth M, Bergstrom A, Shimokawa T, Toftgard R: Inhibition of GLI-mediated transcription and tumor cell growth by small-molecule antagonists. Proc Natl Acad Sci U S A 2007, 104:8455-8460.

12. Lauth M, Toftgard R: Non-canonical activation of GLI transcription factors. Cell Cycle 2007, 6:2458-2463.

13. Lauth M, Toftgard R: The Hedgehog pathway as a drug target in cancer therapy. Curr Opin Investig Drugs 2007, 8:457-461.

14. Mimeault $M$, Batra SK: Frequent deregulations in the Hedgehog signaling network and cross-talks with the epidermal growth factor receptor pathway involved in cancer progression and targeted therapies. Pharmacol Rev 2010, 62:497-524.

15. Stanton BZ, Peng LF: Small-molecule modulators of the Sonic Hedgehog signaling pathway. Mole Biosyst 2010, 6:44-54

16. Tostar U, Malm CJ, Meis-Kindblom JM, Kindblom LG, Toftgard R, Unden AB: Deregulation of the hedgehog signalling pathway: a possible role for the PTCH and SUFU genes in human rhabdomyoma and rhabdomyosarcoma development. J Pathol 2006, 208:17-25.

17. Kinzler KW, Bigner SH, Bigner DD, Trent JM, Law ML, O'Brien SJ, Wong AJ, Vogelstein B: Identification of an amplified, highly expressed gene in a human Glioma. Cytogenet Cell Genet 1987, 46:639-639.

18. Chi SM, Huang SH, Li CX, Zhang XL, He NG, Bhutani MS, Jones D, Castro CY, Logrono R, Haque A, Zwischenberger J, Tyring SK, Zhang H, Xie J: Activation of the hedgehog pathway in a subset of lung cancers. Cancer Lett 2006, 244:53-60.

19. Thompson MC, Fuller C, Hogg TL, Dalton J, Finkelstein D, Lau CC, Chintagumpala M, Adesina A, Ashley DM, Kellie SJ, Taylor MD, Curran T, Gajjar A, Gilbertson RJ: Genornics identifies medulloblastoma subgroups that are enriched for specific genetic alterations. J Clin Oncol 2006, 24:1924-1931.

20. Thayer SP, di Magliano MP, Heiser PW, Nielsen CM, Roberts DJ, Lauwers GY, Qi YP, Gysin S, Fernández-del Castillo C, Yajnik V, Antoniu B, McMahon M, Warshaw AL, Hebrok M: Hedgehog is an early and late mediator of pancreatic cancer tumorigenesis. Nature 2003, 425:851-856.
21. Taylor MD, Liu L, Raffel C, Hui CC, Mainprize TG, Zhang X, Agatep R, Chiappa S, Gao L, Lowrance A, Hao A, Goldstein AM, Stavrou T, Scherer SW, Dura WT, Wainwright B, Squire JA, Rutka JT, Hogg D: Mutations in SUFU predispose to medulloblastoma. Nat Genet 2002, 31:306-310.

22. Li H, Lui N, Cheng T, Tseng HHK, Yue DS, Giroux-Leprieur E, Do HT, Sheng Q, Jin JQ, Luh TW, Jablons DM, He B: Gli as a novel therapeutic target in malignant pleural mesothelioma. PLoS One 2013, 8:e57346.

23. Long B, Zhu HL, Zhu CX, Liu T, Meng WT: Activation of the hedgehog pathway in chronic myelogeneous leukemia patients. J Exp Clin Cancer Res 2011, 30:8-12.

24. Alexaki VI, Javelaud D, van Kempen LCL, Mohammad KS, Dennler S, Luciani F, Hoek KS, Juàrez P, Goydos JS, Fournier PJ, Sibon C, Bertolotto C, Verrecchia F, Saule S, Delmas V, Ballotti R, Larue L, Saiag P, Guise TA, Mauviel A: Gli2-mediated melanoma invasion and metastasis. $J$ Natl Cancer Inst 2010, 102:1148-1159.

25. Inaguma S, Kasai K, Hashimoto M, Ikeda H: GLI1 modulates EMT in pancreatic cancer-letter. Cancer Res 2012, 72:3702-3703.

26. Joost S, Almada LL, Rohnalter V, Holz PS, Vrabel AM, Fernandez-Barrena MG, McWilliams RR, Krause M, Fernandez-Zapico ME, Lauth M: GLI1 inhibition promotes epithelial-to-mesenchymal transition in pancreatic cancer cells. Cancer Res 2012, 72:88-99.

27. Yuan Z, Goetz JA, Singh S, Ogden SK, Petty WJ, Black CC, Memoli VA, Dmitrovsky E, Robbins DJ: Frequent requirement of hedgehog signaling in non-small cell lung carcinoma. Oncogene 2007, 26:1046-1055.

28. Bosco-Clement G, Zhang F, Chen Z, Zhou HM, Li H, Mikami I, Hirata T, Yagui-Beltran A, Lui N, Do HT, Cheng T, Tseng HH, Choi H, Fang LT, Kim IJ, Yue D, Wang C, Zheng Q, Fujii N, Mann M, Jablons DM, He B: Targeting Gli transcription activation by small molecule suppresses tumor growth. Oncogene 2013, 33:2087-2097.

29. Gialmanidis IP, Bravou V, Amanetopoulou SG, Varakis J, Kourea H, Papadaki H: Overexpression of hedgehog pathway molecules and FOXM1 in non-small cell lung carcinomas. Lung Cancer 2009, 6 66:64-74.

30. Raz G, Allen KE, Kingsley C, Cherni I, Arora S, Watanabe A, Lorenzo CD, Edwards VDK, Sridhar S, Hostetter G, Weiss GJ: Hedgehog signaling pathway molecules and ALDH1A1 expression in early-stage non-small cell lung cancer. Lung Cancer 2012, 76:191-196.

31. Azmi AS: Unveiling the role of nuclear transport in epithelial-to-mesenchymal transition. Curr Cancer Drug Targets 2013, 13:906-914.

32. Ng JMY, Curran T: The Hedgehog's tale: developing strategies for targeting cancer. Nat Rev Cancer 2011, 11:493-501.

33. LoRusso PM, Rudin CM, Reddy JC, Tibes R, Weiss GJ, Borad MJ, Hann CL, Brahmer JR, Chang I, Darbonne WC, Graham RA, Zerivitz KL, Low JA, Von Hoff DD: Phase I trial of hedgehog pathway inhibitor vismodegib (GDC-0449) in patients with refractory, locally advanced or metastatic solid tumors. Clin Cancer Res 2011, 7:2502-2511.

34. Sekulic A, Migden MR, Oro AE, Dirix L, Lewis KD, Hainsworth JD, Solomon JA, Yoo S, Arron ST, Friedlander PA, Marmur E, Rudin CM, Chang AL, Low JA, Mackey HM, Yauch RL, Graham RA, Reddy JC, Hauschild A: Efficacy and safety of Vismodegib in advanced basal-cell carcinoma. N Engl J Med 2012, 366:2171-2179.

35. Dlugosz A, Agrawal S, Kirkpatrick P: Vismodegib. Nat Rev Drug Discov 2012, 11:437-438.

36. Agarwal V, Lind MJ, Cawkwell L: Targeted epidermal growth factor receptor therapy in malignant pleural mesothelioma: Where do we stand? Cancer Treat Rev 2011, 37:533-542.

doi:10.1186/1756-9966-33-34

Cite this article as: Yue et al: Hedgehog/Gli promotes epithelial-mesenchymal transition in lung squamous cell carcinomas. Journal of Experimental \& Clinical Cancer Research 2014 33:34. 